\title{
Viabilidade e Fertilização in vitrode 0ócitos Bovinos após Vitrificação em Solução 6 M de DMSO
}

\section{Autor: Sérgio Galbinski}

Orientador: Prof. Dr. Arnaldo Nicola Ferrari

Co-orientador: Prof. Dra. Adriana Bos-Mikich

Dissertação de Mestrado, apresentada ao Programa de Pós-Graduação em Medicina - Mestrado em Clínica Médica da Faculdade de Medicina da UFRGS - Universidade Federal do Rio Grande do Sul, em 8 de novembro de 2001.

Objetivo: Avaliar a técnica de criopreservação por vitrificação em DMSO $6 \mathrm{M}$ para oócitos bovinos maturados in vitro e os efeitos do tempo de exposição às soluções de vitrificação em temperatura ambiente. Delineamento: Estudo experimental tipo coorte.

Materiais e métodos: Ovários foram obtidos em frigorífico local e transportados ao laboratório. Os complexos cumulus-oócito foram aspirados de folículos de 2 a 8 $\mathrm{mm}$ de diâmetro. Oócitos bovinos foram maturados in vitro por 18-22 h. Para vitrificação, os oócitos foram colocados em solução 1,5 M de DMSO por $5 \mathrm{~min}$, transferidos para solução 3,9 M de DMSO, pipetados em solução $6 \mathrm{M}$ de DMSO para palhetas e estocados em nitrogênio líquido. No primeiro grupo experimental, a exposição ao DMSO em temperatura ambiente tomou até $60 \mathrm{~s}$ e no segundo grupo, não ultrapassou $30 \mathrm{~s}$. Para descongelamento, as palhetas foram expostas ao ar por $10 \mathrm{~s}$, colocadas banho-maria por $10 \mathrm{~s}$ e seu conteúdo expelido e mantido em solução de sacarose por $5 \mathrm{~min}$. No terceiro grupo, os oócitos foram processados, envasados, mas não vitrificados. Todos os oócitos recuperados foram inseminados. Para controle, oócitos frescos, maturados in vitro, foram inseminados.

Resultados: Após vitrificação, 69,1\% e 59,8\% dos oócitos foram recuperados nos grupos de $30 \mathrm{~s}$ e $60 \mathrm{~s}$, respectivamente e, 24 horas após inseminação, 93\% e 89,1\% deles pareceram morfologicamente normais, respectivamente. No terceiro grupo, $75,6 \%$ foram recuperados, sendo 84,6\% destes viáveis 24 horas após inseminação. Não ocorreu fertilização nos grupos experimentais. Entre os controles frescos, $65,4 \%$ dos oócitos foram fertilizados.

Conclusão: A vitrificação utilizando DMSO 6 M não é uma metodologia aplicável para a criopreservação de oócitos bovinos maturados in vitro. A redução do tempo de exposição às SV, não superou o efeito deletério sobre a capacidade fertilizadora dos oócitos. Estes resultados sugerem que aprimoramentos da técnica são necessários para proteção da zona pelúcida e do oolema.

Palavras-chave: Infertilidade. Fertilização in vitro. Oócitos. Criopreservação.

\section{RBGO}

É uma publicação da
FEBRASGO

que aceita artigos provenientes de ginecologistas, obstetras e de outras

especialidades.

Portanto, publique!!!

Mande já seu artigo para RBGO 